\title{
Agglomeration of Hydrolyzed Collagen with Blackberry Pulp in a Fluidized Bed
}

\author{
Viegas, T. R. ${ }^{a^{*}}$; Taranto, O. P. ${ }^{a}$ \\ ${ }^{a}$ School of Chemical Engineering. University of Campinas, Campinas, Brazil \\ *E-mail of the corresponding author: thaynaviegas@gmail.com
}

\begin{abstract}
Hydrolyzed collagen (HC) is a fine powder applied in the pharmaceutical and food industries which has shown good results in the treatment of diseases related to bones, skin and joints. In this study, HC particles were agglomerated in order to increase particle size, optimizing its use as a food ingredient, its handling and its storage. Agglomeration is a process that not only enlarge the size of fine particles, but also improves its properties, such as instantanization time and flowability. The aim of this work was the agglomeration of HC in a fluidized bed having blackberry pulp as a liquid binder. A full factorial design $2^{2}$ was used to study the effect of the temperature of the fluidizing air $(60,70$, $\left.80^{\circ} \mathrm{C}\right)$ and the flow rate of the liquid binder $(0.8,1.2,1.6 \mathrm{~mL} / \mathrm{min})$ on the process yield, mean particle size, water activity and total anthocyanins content. It was observed that anthocyanins content from the blackberry pulp had higher values with lower temperatures. Water activity had lower values with higher temperatures, but in all conditions, it was lower than 0.6. The enlargement of the granules was observed in all conditions studied, increasing up to $275 \%$. Process yield varied from 67,9 to $80,0 \%$. In all conditions, the instantanization time and flowability improved compared to hydrolyzed collagen before agglomeration.
\end{abstract}

Keywords: hydrolyzed collagen; agglomeration; granulation; fluidized bed; blackberry pulp 


\section{Introduction}

Chronic non-communicable diseases (NCD) are responsible for almost $60 \%$ of the global mortality rate [1] and for $72 \%$ of the Brazilian mortality rate [2]. Chronic respiratory diseases, cardiovascular diseases and diabetes are examples of NCD, caused mainly by poor diet and physical inactivity. To change that, it is essential to increase the consumption of vegetables, fruits, cereals and replace foods rich in sodium or simple carbohydrates [2]. To contribute to the reversal of such a scenario, this work presents a feasible production method of agglomerated $\mathrm{HC}$ as an instant functional food and protein supplement rich in anthocyanins.

Agglomeration, also known as granulation, increases the size of particles, which then are called granules or agglomerates. This process is applied in the chemical, pharmaceutical and food industries to improve particle handling, storage and transportation, as well as particles' properties, such as flowability and instantanization time [3]. Regarding the food industry in particular, agglomeration enables the granules to achieve specific properties and size intervals [4].

The agglomeration process using a fluidized bed, although complex, shows many advantages, such as good heat and mass exchange and the performing of all steps of a given process in the same equipment [5]. The agglomeration process occurs when the particles are fluidized and dried by the heated air which is admitted through the bottom of the bed, while an atomization nozzle humidifies the particles with a binder.

This work aims to find the most suitable condition (binder flow rate and fluidizing air temperature) for the agglomeration of $\mathrm{HC}$ in a fluidized bed, using blackberry pulp as a binder in order to increase the particles' sizes, improve the particles' properties and add the nutritional benefits of blackberry pulp to the agglomerates. Collagen has been studied for over a century and its demand in the market only increases [6], because it is a protein product with amino acids that are essential to the human diet [7], which shows positive results in the treatment of diseases related to the bones, skin and joints $[8,9,10]$. Blackberry pulp, on the other hand, is rich in vitamins, iron and anthocyanins, which helps in the prevention of degenerative diseases such as cancer and diabetes [11].

\section{Materials and Methods}

\subsection{Equipment and process variables}

The lab-scale fluid bed (Fig. 1) used to perform the experiments has a cylindrical Plexiglas base and column (11). On top, there is a cyclone (13) to collect the elutriated fine particles. In the entrance of the bed, a perforated plate (10) distributes the air uniformly. The inlet air is supplied by a 7.5 HP WEG (2) air blower, delivered to the system by a 2 " internal diameter galvanized steel pipe, and then passes through a bed of silica gel (5). The blower is connected 
to a frequency inverter (2a) (WEG CFW 08). The air velocity was determined by a hot wire anemometer (IMPAC, Delta Ohm, HD2903TC2.2) (4).

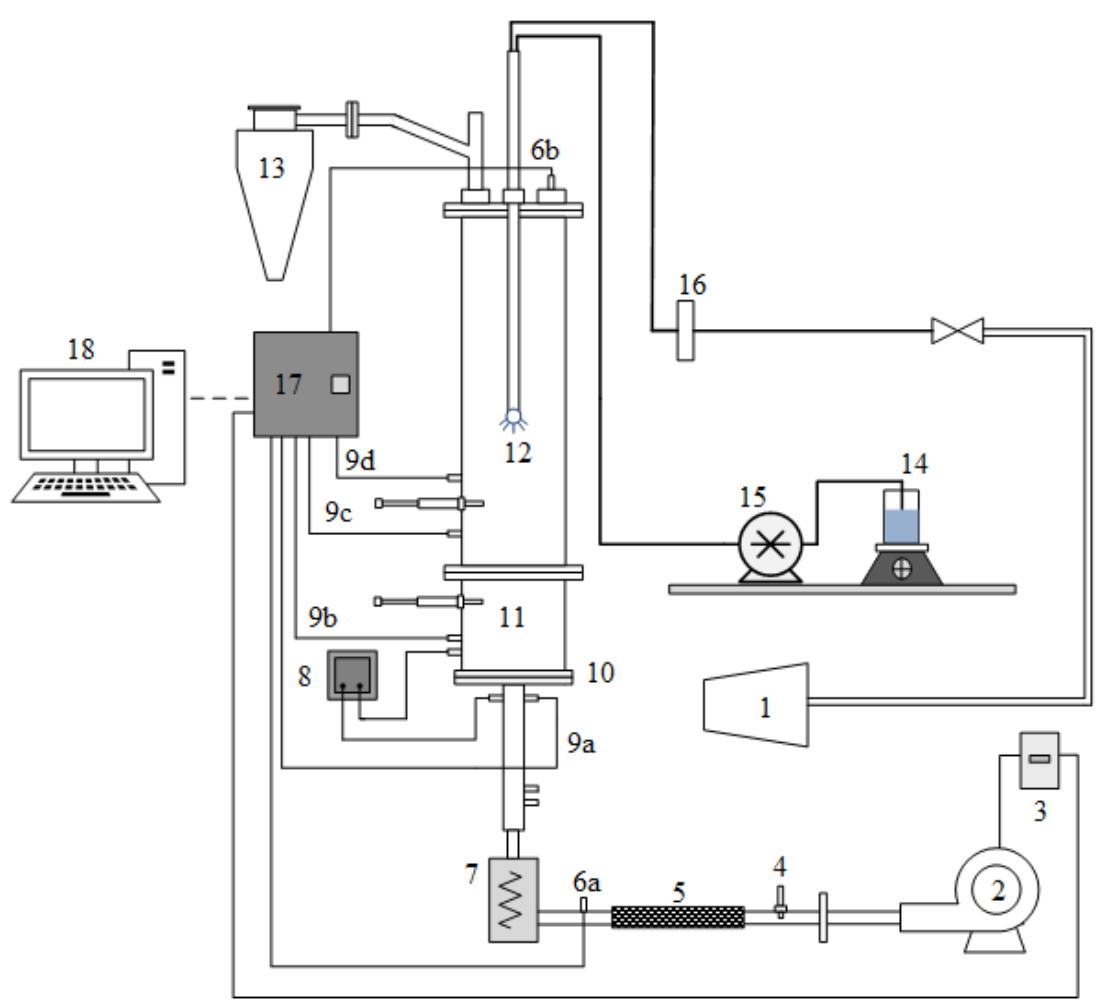

Fig 1. Experimental System

The air temperature in the plenum chamber was adjusted by a set of electrical resistors (7) controlled by a PID regulator (Novus, N1100). Pt-100 Thermoresistances (Novus, Ø $3.0 \mathrm{~mm}$ $\mathrm{x} 100 \mathrm{~mm}$ ) measure the temperature of the system in the plenum chamber (9a) and the other three points (9b, 9c and 9d) the column. Two sensors (6a and 6b) (RHT-XS, Novus) provide the values of relative humidity and dry bulb temperature at the input (before the resistors) and in the fluid bed output, controlled by a PID regulator (Novus, N1200). The pressure drop in the bed is provided by a differential transducer (Cole Parmer, XLDP) (8).

A peristaltic pump (15) (Cole Parmer, 7780-60, Masterflex L / S) carries blackberry pulp (14) used as a binder in the granulation process. A double fluid type spray nozzle (Spraying Systems, SU12A) produces a cone-shaped spray of droplets. The atomizing pressure for obtaining the droplets is provided by a compressor (MSV 40 Max, 10 horsepower) (1) and 
regulated by a Norgren pressure regulator. This compressed air is filtered (16) (Parker, Hannifin Ltd.) before being used in the atomization.

The pressure, temperature and humidity sensors are connected to a computer, by a data acquisition system, which consists of a NI cDAQ-9172 (National Instrument) (17) board that collects the data at a defined sampling rate. LabVIEW 8.6TM (Virtual Instrument Engineering Workbench) software, by means of virtual instruments (VI), makes the interface between the process and the data acquisition board. The program was installed on an Intel ${ }^{\circledR}$ Core i5 computer with 4.0 GB of RAM (18).

\subsection{Water Activity}

The water activity was measured by AQUALAB S3TE.

\subsection{Particle Diameter}

The HC particles were observed using a digital microscope (Dino-Lite AM4515ZT) after being dispersed on several glass slides to obtain at least 500 particles. The images were analyzed using the software IMAGE J v1.50i (National Institutes of Health, USA), allowing the calculation of the particles mean diameters[12].

\subsection{Anthocyanins Content}

The anthocyanins content was determined using the differential $\mathrm{pH}$ method [13].

\subsection{Process Yield}

The process yield was calculated by the ratio of the mass of $\mathrm{HC}$ fed per the final mass in the fluid bed.

\subsection{Instantanization time}

The instantanization time was considered the time required for $3 \mathrm{~g}$ of the sample to disappear from the water surface $\left(60 \mathrm{~mL}\right.$ at $\left.27^{\circ} \mathrm{C}\right)$, using an apparatus described by [14].

\subsection{Flowability}

The flowability of raw and granulated $\mathrm{HC}$ was obtained using the Carr index (Table 1). The powder is submitted to 500, 750, or 1250 taps in the equipment Autotap Tap Density Analyzer (DAT-4, Quantachrome instruments ${ }^{\circledR}$ ), following the standard 616 of the North American Pharmacopeia [15]. 
Table 1. Classification of powder flowability based on the Carr index

\begin{tabular}{cc}
\hline Icarr (\%) & Flowability \\
\hline$<15$ & Very Good \\
$15-20$ & Good \\
$20-35$ & Fair \\
$35-45$ & Bad \\
$>45$ & Very Bad \\
\hline
\end{tabular}

\subsection{Moisture Content}

The humidity was determined by a Moisture Analyzer with halogen light heating (HR83, Mettler Toledo).

\section{Results and Discussion}

The yield was higher with the lowest binder flow rate and with the maximum or minimum temperature $\left(\mathrm{T}_{\mathrm{f}}\right)$ used, resulting in a surface plot with significant curvature (Fig 2-a). The biggest particles $(275 \%$ bigger than raw $\mathrm{HC}$ ) occurred with lower binder flow rate and temperature (Fig. 2-b), since in this condition the moisture content was lower. Partial defluidization was observed using higher values of binder flow rate, reducing the impact between particles and, therefore, their size, as also observed by [16]. As for the moisture content (Fig. 2-c), lower binder flow rate and higher temperature resulted in a minimum value of moisture content, as expected and observed by [16]. However, even at higher temperature, the binder flow rate had more impact in the moisture content, since higher values of $\mathrm{Q}_{\text {lig }}$ resulted in a moister agglomerated HC. The AT (dry basis) was higher when the temperature was minimum (Fig. 2-d), as the degradation of anthocyanins was minimum in this case.

Water activity was lower than raw $\mathrm{HC}$ and higher than Commercial HC (Table 2), and since all the values were aw $<0.6$, microbial growth will not happen in the powder [17]. The instantanization time of agglomerated $\mathrm{HC}$ reduced considerably when compared to raw $\mathrm{HC}$ and Commercial HC because of the size and morphological changes in the particles, as observed by [17]. Therefore, the bigger the HC particles, the faster was the IT. Moreover, the flowability of agglomerated HC improved from Fair (raw HC) to Good or Very Good. 

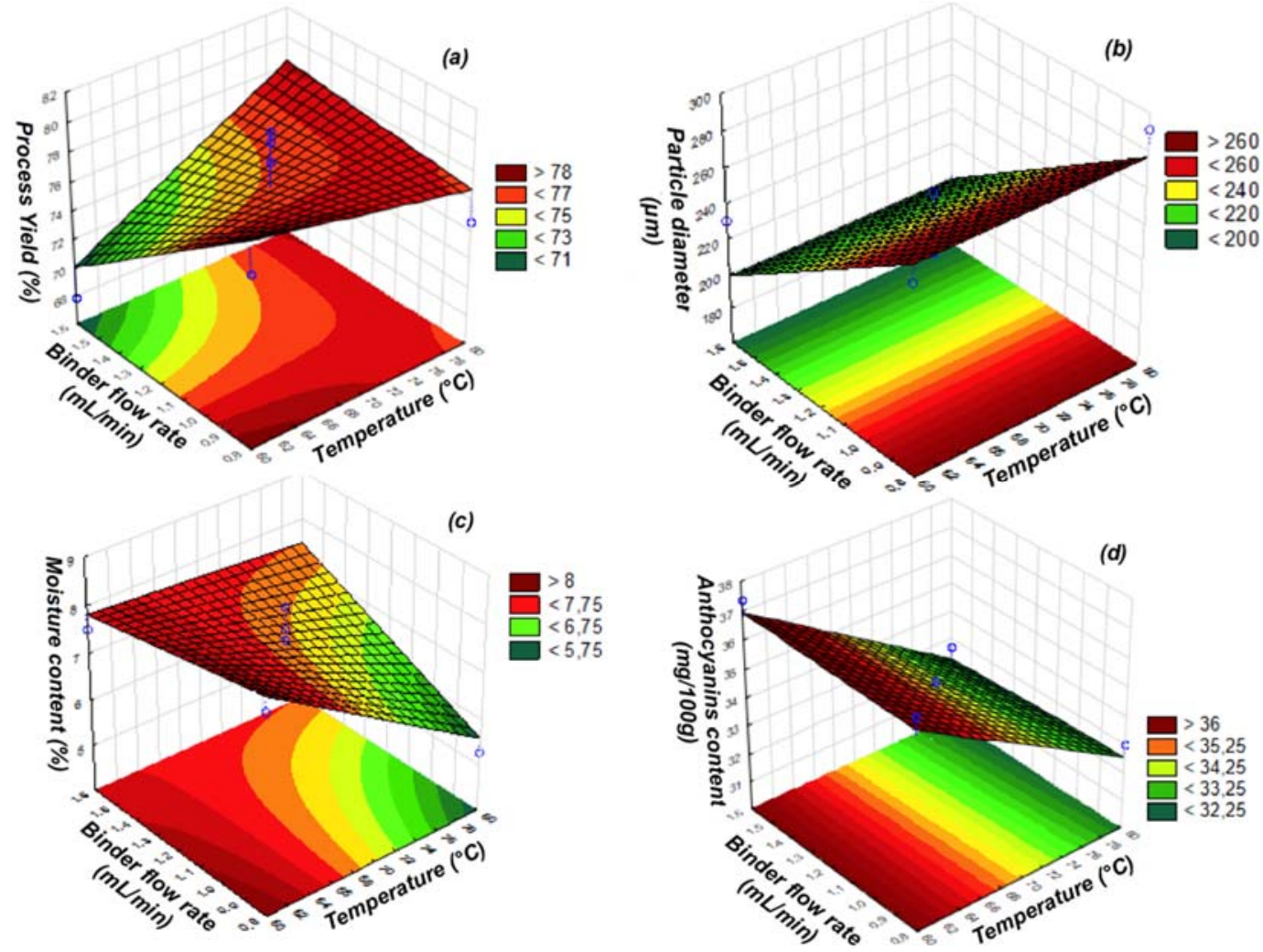

Fig 2. Surface plot of Process Yield, Particle diameter, Moisture content and Anthocyanins content versus Temperature and Binder flow rate.

Table 2. Results of the experimental design (nozzle height: $300 \mathrm{~mm}$, mass of sample: $500 \mathrm{~g}$ ).

\begin{tabular}{|c|c|c|c|c|c|c|c|c|c|}
\hline $\begin{array}{c}\text { Experimental } \\
\text { Run }\end{array}$ & $\begin{array}{c}T_{f} \\
\left({ }^{\circ} \mathrm{C}\right)\end{array}$ & $\begin{array}{c}Q_{\text {lig }} \\
(\mathrm{mL} / \mathrm{min})\end{array}$ & $\begin{array}{l}\text { Yld } \\
(\%)\end{array}$ & $\begin{array}{c}\text { Mst } \\
(\% \text { d.b. })\end{array}$ & $\begin{array}{c}d p_{m} \\
(\mu m)\end{array}$ & $\begin{array}{c}A T \\
(\mathrm{mg} / \mathrm{100g}) \\
\end{array}$ & $\begin{array}{l}I T \\
(s)\end{array}$ & $a w$ & $\begin{array}{c}\text { Icarr } \\
(\%)\end{array}$ \\
\hline $\mathrm{HC}$ & - & - & - & 7.45 & 96.96 & - & 170 & 0.490 & 22.18 \\
\hline 1 & $80(1)$ & $1.6(1)$ & 76.2 & 7.17 & 172.03 & 32.67 & 2.2 & 0.396 & 17.39 \\
\hline 2 & $80(1)$ & $0.8(-1)$ & 74.6 & 5.27 & 291.23 & 33.04 & 1.65 & 0.386 & 14.29 \\
\hline 3 & $70(0)$ & $1.2(0)$ & 78 & 7.71 & 218.46 & 34.91 & 2.2 & 0.425 & 13.91 \\
\hline 4 & $70(0)$ & $1.2(0)$ & 79.3 & 7.47 & 251.64 & 33.55 & 2.15 & 0.420 & 16.67 \\
\hline 5 & $70(0)$ & $1.2(0)$ & 80 & 8.17 & 233.14 & 33.66 & 2.1 & 0.423 & 16.95 \\
\hline 6 & $60(-1)$ & $1.6(1)$ & 67.9 & 7.5 & 230.62 & 37.39 & 2.25 & 0.437 & 12.39 \\
\hline 7 & $60(-1)$ & $0.8(-1)$ & 77.8 & 8.24 & 266.64 & 37.31 & 1.85 & 0.430 & 13.51 \\
\hline $\begin{array}{c}\text { Commercial } \\
\mathrm{HC}^{1}\end{array}$ & - & - & - & 8.15 & 198.2 & - & 9 & 0.404 & 16.52 \\
\hline
\end{tabular}

${ }^{1}$ Commercial Agglomerated HC already sold in market (Commercial HC - GELITA) 


\section{Conclusions}

The central points (tests 4, 5 and 6) presented the best overall results: they presented bigger particles than the ones of Commercial HC, an increase of more than $200 \%$ compared to raw HC. In those tests, the process yield was, in average, $79.1 \%$. The moisture content values had an average of $7.78 \%$, lower than that of the Commercial HC. The AT content values were low in all the tests and further studies are needed to reduce the degradation of anthocyanins by light and high temperature. The water activity values were in a range that assures product safety for all the tests and the instantanization time decreased in relation to raw $\mathrm{HC}$ and Commercial HC. Thus, we produced a powder larger in size, with adequate moisture and process yield, which can be commercialized or used as an ingredient rich in anthocyanins.

\section{Nomenclature}

$\begin{array}{lll}\boldsymbol{T}_{\boldsymbol{f}} & \text { Fluidizing temperature } & { }^{\circ} \mathrm{C} \\ \boldsymbol{Q}_{\text {lig }} & \text { length co-ordinate } & \mathrm{M} \\ \text { Yld } & \text { Yield } & \% \\ \boldsymbol{M} \boldsymbol{s t} & \text { Moisture content } & \% \mathrm{~d} . \mathrm{b} . \\ \boldsymbol{d} \boldsymbol{p}_{\boldsymbol{m}} & \text { Particle mean diameter } & \mu \mathrm{m} \\ \boldsymbol{A T} & \text { Anthocyanins content } & \mathrm{mg} / 100 \mathrm{~g} \\ \boldsymbol{I T} & \text { Instantanization time } & \mathrm{s} \\ \boldsymbol{a} \boldsymbol{w} & \text { Water activity } & - \\ \boldsymbol{I} \boldsymbol{c a r r} & \text { Carr Index } & \%\end{array}$

\section{References}

[1] Unwin N, Alberti KG. Chronic non-communicable diseases. Ann Trop Med Parasitol. 2006;100(5-6):455-64.

[2] Minestério da Saúde. Plano de estratégias de Ações Estratégicas para o Enfrentamento das Doenças Crônicas Não Transmissíveis no Brasil 2011-2022. Ministério da Saúde. Retrieved January 18, 2018, from http://bvsms.saude.gov.br/bvs/publicacoes/plano_acoes_enfrent_dent_2011.pdf

[3] Saleh, K. and Guigon, P., 2009a. Mise en oeuvre des poudres - Granulation humide: bases et théorie. Techniques de l'ingénieur, J2253 V1, 1-14.

[4] Smith, P. G. (2007). Applications of fluidisation in food processing. Oxford: Blackwell Science.

[5] Saleh, K. and Guigon, P., 2009b. Mise en oeuvre des poudres - Techniques de granulation: humide et liants. Techniques de l'ingénieur, 1-14. 
[6] Vinnars, E.; Wilmore, D. (2003). History of parenteral nutrition. Journal of Parenteral and Enteral Nutrition, 27(3), 225-231.

[7] Bilek, S. E.; Bayram, S. K. (2015). Fruit juice drink production containing hydrolyzed collagen. Journal of Functional Foods, 14, 562-569.

[8] Moskowitz, R. W. (2000). Role of collagen hydrolysate in bone and joint disease. Seminars in Arthritis and Rheumatism, 30(2), 87-99. doi:10.1053/sarh.2000.9622

[9] Sibilla, S.; Borumand, M. (2015). Effects of a nutritional supplement containing collagen peptides on skin elasticity, hydration and wrinkles. Journal of Medical Nutrition and Nutraceuticals, 4(1), 47.

[10] Proksch, E.; Segger, D.; Degwert, J. et al. Oral supplementation of specific collagen peptides has beneficial effects on human skin physiology: a double-blind, placebocontrolled study. Skin Pharmacol Physiol. 2014;27(1):47-55.

[11] Sancho, R. A., \& Pastore, G. M. (2012). Evaluation of the effects of anthocyanins in type 2 diabetes. Food Research International, 46(1), 378-386.

[12] Dacanal G.C., Menegalli F. C., 2010, Selection of operational parameters for the production of instant soy protein isolate by pulsed fluid bed agglomeration, Powder Technology, 203, 565-573,

[13]LEE, Jungmin; DURST, Robert W; WROLSTAD, Ronald E. Determination of Total Monomeric Anthocyanin Pigment Content of Fruit Juices, Beverages, Natural Colorants, and Wines by the $\mathrm{pH}$ Differential Method: Collaborative Study. AOAC International, [s.l.], v. 88, n. 5, p.1269-1278, set. 2005.

[14] Hogekamp, S.; Schubert, H. Rehydration of food powders, Food Sci. Technol. Int. 9 (2003) 223-235.

[15]U.S. PHARMACOPEIAL CONVENTION. 616: Bulk Density and Tapped Density of Powders. United States: 2011 The United States Pharmacopeial Convention, 2011.

[16] Andreola K., Butzge J.J., Silva C.A.M., Kis L.S., Rocha S.C.S, Taranto O.P, 2015, Effect of operating conditions on the agglomeration and drying of hydrolyzed collagen in a fluidized bed, First Nordic Baltic Drying Conference, 17 -19 June, Gdansk, Poland.

[17] Rahman, S. Food Properties Handbook. CRC Press, 2008. 